Article

\title{
Numerical Analysis of High-Altitude Inlet Air on Boundary Layer Flow Loss in an Aero-Engine Compressor
}

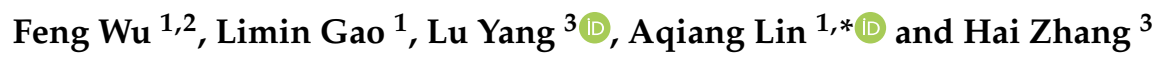 \\ 1 School of Power and Energy, Northwestern Polytechnical University, Xi'an 710129, China; \\ wufeng_nwpu@outlook.com (F.W.); gaolm@nwpu.edu.cn (L.G.) \\ 2 Science and Technology on Altitude Simulation Laboratory, AECC Sichuan Gas Turbine Establishment, \\ Mianyang 621000, China \\ 3 College of Power and Energy Engineering, Harbin Engineering University, Harbin 150001, China; \\ ayanglu@hrbeu.edu.cn (L.Y.); zhanghai83821@163.com (H.Z.) \\ * Correspondence: linaqiang@nwpu.edu.cn
}

Received: 7 July 2020; Accepted: 3 August 2020; Published: 11 August 2020

\begin{abstract}
A numerical analysis is performed to explore the high altitude and high Mach flight on the effect of wall boundary layer loss in the compressor. The accuracy for solution results by the application of the similarity criterion and parameter definition of the air inlet is compared with the existing experimental test result. The results indicate that the radial adverse pressure gradient in the rotor domain gradually increases along the span direction and decreases as flight Mach number increases; meanwhile, the circumferential adverse pressure gradient on the pressure side of the rotor blade is correspondingly larger and less than that on the suction side. In particular, the entropy increase along the streamwise shows a decreasing trend and an increasing trend inside the hub and shroud wall boundary layers, respectively. At 2.1 $\mathrm{Ma}$, the entropy increase in the rotor domains enhances by $24.36-27.80 \%$ inside the shroud boundary layer, relative to the hub boundary layer; however, it decreases by $0.97-8.54 \%$ in the stator domain. With the increase in flight Mach number from 2.1 to 3.4, the average entropy increase reductions in the rotor domain decrease by $18.99-24.97 \%$ within the hub boundary layer and $5.71-8.1 \%$ within the shroud boundary layer. In the stator domain, it drops by $18.45-9.03 \%$ inside the hub boundary layer and $6.88-8.67 \%$ inside the shroud boundary layer. It was therefore found that, as Mach number increases from 2.1 to 3.4, the entropy increase reduction is larger inside the hub boundary layer than inside the shroud boundary layer.
\end{abstract}

Keywords: compressor; boundary layer; high Mach number; similarity criterion; flow loss; entropy increase

\section{Introduction}

The three components of an aero engine mainly include a compressor, a combustion chamber, and a turbine. Among these, the performance of the compressor is also of significance for the aero engine. It compresses the incoming air through high-speed rotating blades and then enhances air pressure [1]. However, the flow loss inside the compressor is critical to the performance of aero engines under high reverse pressure gradients, especially for tip leakage flow and secondary flow [1-3]. Currently, the commercial codes of computational fluid dynamics are usually conducted for numerical analysis, due to the improvement of computational accuracy in the field of turbomachinery [4], flow loss [5], heat transfer [6,7], etc. The previous researchers also substantiated that the numerical simulation has a higher accuracy by comparison with the experimental results $[8,9]$. 
The clearance leakage flow is an important source of flow loss. Berdanier et al. [10] conducted a numerical study on a multi-stage axial compressor. Gbadebo et al. [11] found the inhibitory effect of tip leakage flow on the corner separation. Moreover, Hanan and Qiushi [12] took a 1.5-stage axial compressor as an example to investigate the effect of nonuniform clearance on the flow characteristics. Actually, the effect of clearance leakage flow at different locations has some differences in the flow passage [13]. For the clearance leakage flow loss, some of the researchers also proposed the problem-solving solution to improve the flow structure by the application of the vortex generator and the casing modification [14,15]. Then, Caruana et al. [16] revealed that the shock wave/turbulent boundary layer interaction and flow separation can cause flow instability at the transonic flow condition. Through the simulation calculation of the transonic compressor rotor, the interference of shock wave and wall boundary layer produced radial separation flow from the blade root to the blade tip under the action of the adverse pressure gradient [17]. The presence of separated flow will affect the stall of the compressor. Therefore, the leakage flow and secondary flow inside the compressor are not only important sources of loss but also have important significance for the stability of the compressor. Moreover, it's worth paying attention to the flow loss in the boundary layer inside the flow passage of the compressor.

Because the airflow in the aero engine compressor has fewer stages and a higher single-stage load, it works under higher adverse pressure gradient conditions, which will increase the thickness of the end wall boundary layer and cause high losses [18]. Regarding the improvement of flight altitude and speed, the flow characteristics inside the aero engine transonic compressor are much more complicated. At the same time, due to the shock wave in the transonic compressor, the boundary layer of the suction surface is more likely to separate. Although the previous studies on flow loss in compressors mainly focused on qualitative analysis of losses caused by tip leakage and secondary flow, little attention was paid to quantitative analysis of compressor losses. Therefore, the purpose of this study is to systematically and comprehensively evaluate the impact of high Mach number flight on the boundary layer loss of the aero engine compressor wall. Through the parametric definition of the air inlet and the application of the similarity criterion, the working environment of the aviation compressor with experimental verification under the high Mach condition is obtained. The definition of entropy increase is used to describe the loss in the flow field. Then, the wall boundary layer loss under different Mach numbers is discussed.

\section{Numerical Method and Modelling}

To simulate the performance of the engine compressor at higher speeds and higher altitudes, it is necessary to use similarity and modeling theory to establish the air intake and compressor models. Thus, the one-dimensional modeling parameters of the air intake can be derived as the three-dimensional inlet boundary condition of the compressor. Figure 1 presents the derivation process of compressor boundary conditions at high altitude flight. In addition, the previous work has been concluded that the most important dimensionless criterion is Mach number so that the same equivalent mass flow and equivalent speed are recommended under high-speed flow conditions [1].

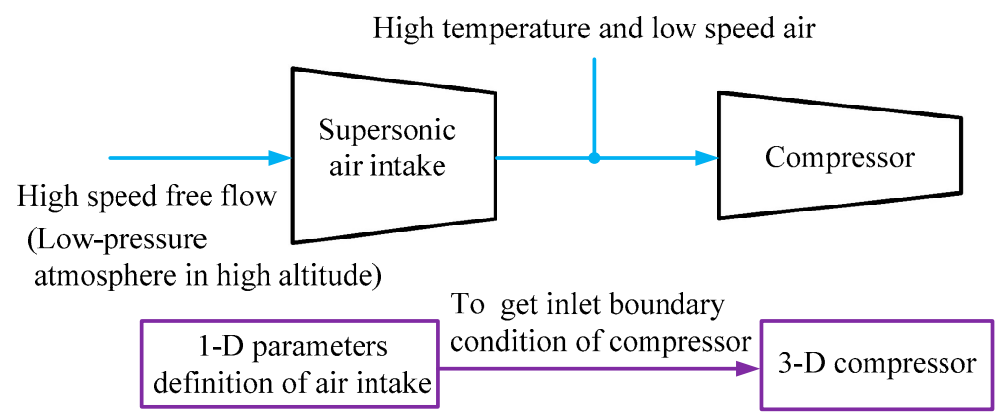

Figure 1. Derivation process of compressor boundary conditions at high altitude flight [1]. 
Therefore, in order to acquire the flow field of the compressor at the high-altitude flight environment, the equivalent mass flow $(\bar{G})$ and equivalent speed $(\bar{n})$ of the compressor should remain unchanged [19]. This modeling method can ensure that the two flow fields are approximately similar. Here, the similarity criterion can be determined by Equation (1). Moreover, the detailed derivation process is presented in [1].

$$
(\bar{G}, \bar{n})=\left(G \sqrt{T_{t}} / P_{t}, n / \sqrt{T_{t}}\right)
$$

where, $T_{t}$ denotes the total temperature on the compressor inlet, and $P_{t}$ denotes the total pressure at the inlet of the compressor.

For the present work, the numerical method is employed to simulate the flow field of Stage-35 compressor which is according to the requirements of the typical aircraft engine design of the transonic compressor [20]. The Stage-35 compressor is composed of 46 stator blades and 36 rotor blades with a tip clearance of $0.408 \mathrm{~mm}$. The simplified geometric model and its mesh are shown in Figure 2. Moreover, mesh refined processing near the boundary layer is also used to capture near-wall effects and to cater for required Y-plus values. Then, a mesh independence study is conducted and, finally, a total grid cell number of $1.5 \times 10^{6}$ is used for the present study.

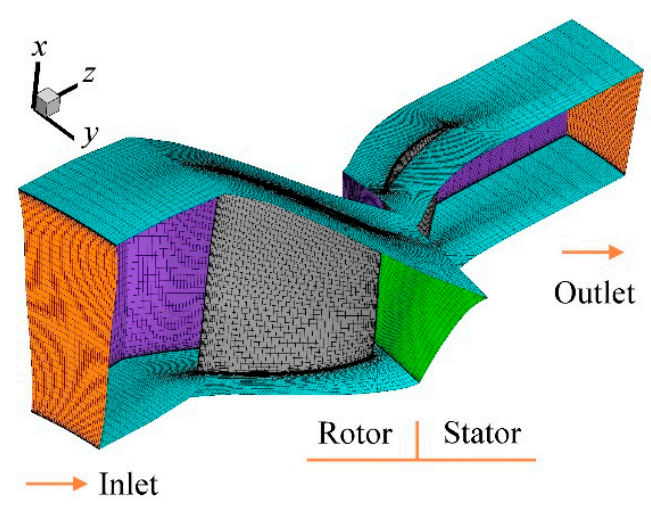

Figure 2. Schematic diagram of NASA Stage-35 compressor.

The boundary conditions for inlet and outlet of Stage- 35 are assigned from outlet parameter definitions of air intake in [1]. Total temperature and total pressure are applied at the compressor inlet. Static pressure is imposed on the compressor outlet. To determine the backpressure of the compressor, it should be the same equivalent mass flow of 0.00338 and equivalent speed of 1012.5 between the prototype (at ground conditions) and the similarity flow field (at high altitude condition). The boundaries at the circumferential direction are simplified as the rotational periodic interfaces, and the interface between rotor outlet and stator inlet applies the mixing plane method. Then, all other walls are set to adiabatic and non-slip velocity boundary conditions. According to [21], six types of turbulence models are analyzed in the NASA Stage-35 compressor. Since the SST $\kappa-\omega$ turbulence model employs a mixed-function, the model maintains the $\omega$ equation for near-wall regions, while being switched to $\varepsilon$ equation for the areas far from the wall [22]. Moreover, the numerical results can be revealed to be consistent with experimental data; thus, the SST $\kappa-\omega$ turbulence model can be applied as it shows better results by comparison with the other turbulence models.

For high-temperature incoming airflow, thermal conductivity $(\lambda)$ and kinematic viscosity $(\mu)$ are calculated by Sutherland's equation [21]. So, the physical properties for $C_{p}, \mu$ and $\lambda$ as the temperature changes are shown in Figure 3. 


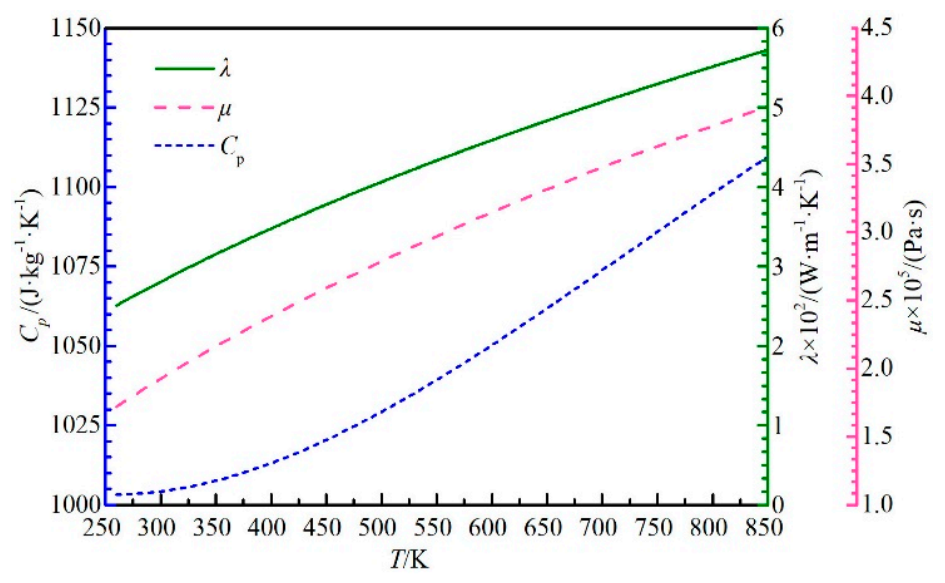

Figure 3. Properties of dry air only varying with temperature [1].

The present research uses the commercial software ANSYS-Fluent based on the 3-D compressible, pressure-based solver with the implicit formulation and Simple-C pressure-velocity coupling algorithm. Moreover, the high resolution is selected for the advection format and turbulence numerical calculation. When all terms reach the $1 \times 10^{-6}$ order residual target, and the mass and energy imbalance percentage is less than $0.05 \%$, the final solution can get the convergent.

\section{Numerical Analysis and Result}

\subsection{Verification of Solution Accuracy}

In order to verify the feasibility and accuracy of the application of similar criteria, Figure 4 shows the comparative flow field on the Mach number profile of the compressor inlet. It can be revealed that the Mach number contours at each basic section along the radial direction tend to be consistent, which conforms to the high similarity of the inlet velocity triangle and conforms to the flow characteristics of the transonic compressor.

(a)

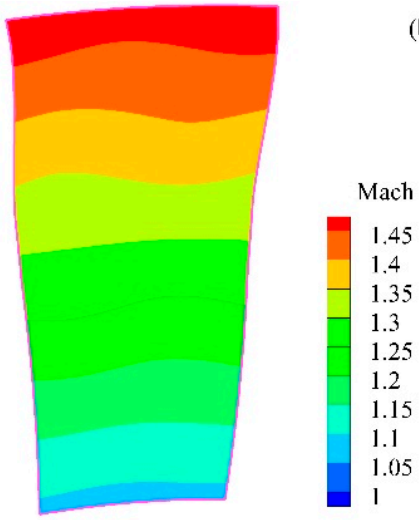

(b)

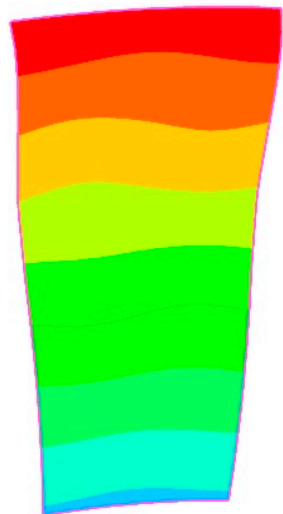

Figure 4. Comparisons of inlet Mach number distribution for flow fields between (a): prototype and (b): similarity flow field $[1,19]$.

Figure 5 gives the compressor characteristics for both the similarity flow field and prototype. It is demonstrated that, for efficiency and total-pressure ratio, the numerical results from the similarity flow field are located between the design value and the experimental values, and the trend of two characteristic lines are similar. It is, therefore, feasible and suitable for the application of similarity criterion into high altitude and high Mach flight for the present study. 

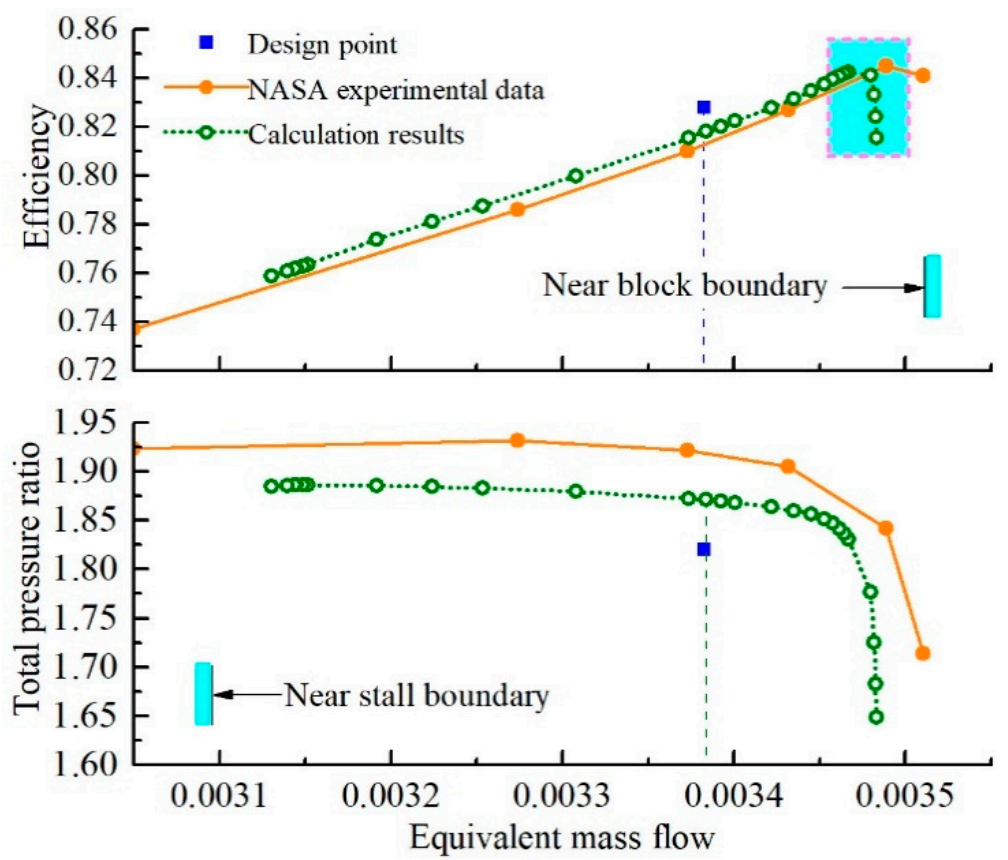

Figure 5. Comparisons of compressor characteristics between numerical and experimental results [1,19].

\subsection{Analysis of the Flow Loss}

The flight trajectories for dynamic pressures of $45 \mathrm{kPa}, 50 \mathrm{kPa}$, and $60 \mathrm{kPa}$ are given in Figure 6 . In order to pay attention to the impact of high Mach flight on the flow loss of the aero engine compressor, the research objects are carried out for different conditions of flight Mach (from 2.1 Ma to 3.4 Ma) at a flight dynamic pressure of $45 \mathrm{kPa}$. As shown in Figure 6, for a given dynamic pressure, the flight Mach gradually improves as flight altitude increases. Meanwhile, for a given flight Mach, the dynamic pressure also enhances with the increase in flight altitude.

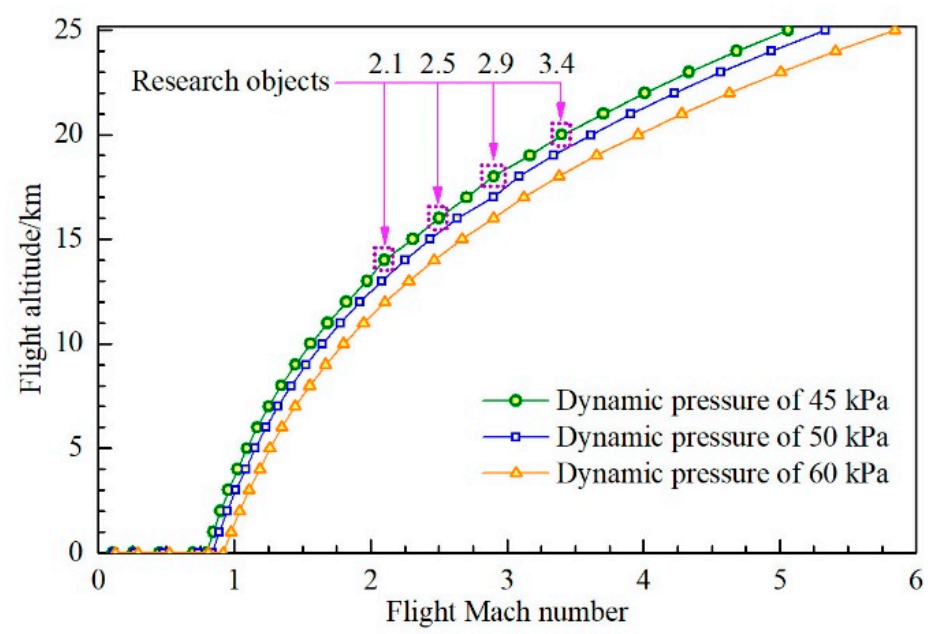

Figure 6. High-altitude flight trajectory by maintaining a constant of dynamic pressure.

The thermodynamic process can directly reflect the variation rule and energy conversion of the state parameter in the compressor. Figure 7 gives the detailed thermodynamic process for 2.1-3.4 Ma under $45 \mathrm{kPa}$ dynamic pressure. Here, the state points $1^{\prime}, 2^{\prime}$ and $3^{\prime}$ correspondingly represent the compressor inlet, rotor outlet and compressor outlet. In the pressure-volume diagram (Figure 7a), the flow at higher flight Mach has a higher pressure and lower specific volume, indicating that the mass flow 
exhibits an upward trend as flight Mach increases, especially for 3.4 Ma. Among the four flight Mach, the specific volume of compressor inlet and outlet at $2.1 \mathrm{Ma}$ are $1.123 \mathrm{~m}^{3} / \mathrm{kg}$ and $0.83 \mathrm{~m}^{3} / \mathrm{kg}$, respectively, so its specific-volume reduction is $0.293 \mathrm{~m}^{3} / \mathrm{kg}$. By comparison, the relative specific-volume reductions at 2.9 $\mathrm{Ma}$ and $3.4 \mathrm{Ma}$ are correspondingly decreased by $0.162 \mathrm{~m}^{3} / \mathrm{kg}$ and $0.095 \mathrm{~m}^{3} / \mathrm{kg}$. This can be attributed primarily to the increasing air density, velocity and temperature on the compressor inlet so that the pressure energy is enhanced. Meanwhile, the specific-volume reductions in the compressor are dropped by approximately $26.1 \%$ (i.e., $0.293 \mathrm{~m}^{3} / \mathrm{kg} / 1.123 \mathrm{~m}^{3} / \mathrm{kg}=26.1 \%$ ), $28.94 \%$ and $30.21 \%$, respectively, at 2.1 Ma, 2.9 Ma and 3.4 Ma, revealing the that total pressure ratio of the compressor is gradually heightened as the flight Mach increases. In the temperature-entropy diagram (Figure 7b), the flow at higher flight Mach has higher entropy and temperature. However, it can be seen that the relative temperature increases are $69.24 \mathrm{~K}, 100.96 \mathrm{~K}$, and $122.07 \mathrm{~K}$, respectively, at $2.1 \mathrm{Ma}, 2.9 \mathrm{Ma}$ and 3.4 Ma correspondingly representing $18 \%, 18.88 \%$ and $18.91 \%$ increases. Notably, this observation reveals that the total temperature ratio of the compressor enhances as flight Mach increases, probably leading to an effect on the compressor performance.

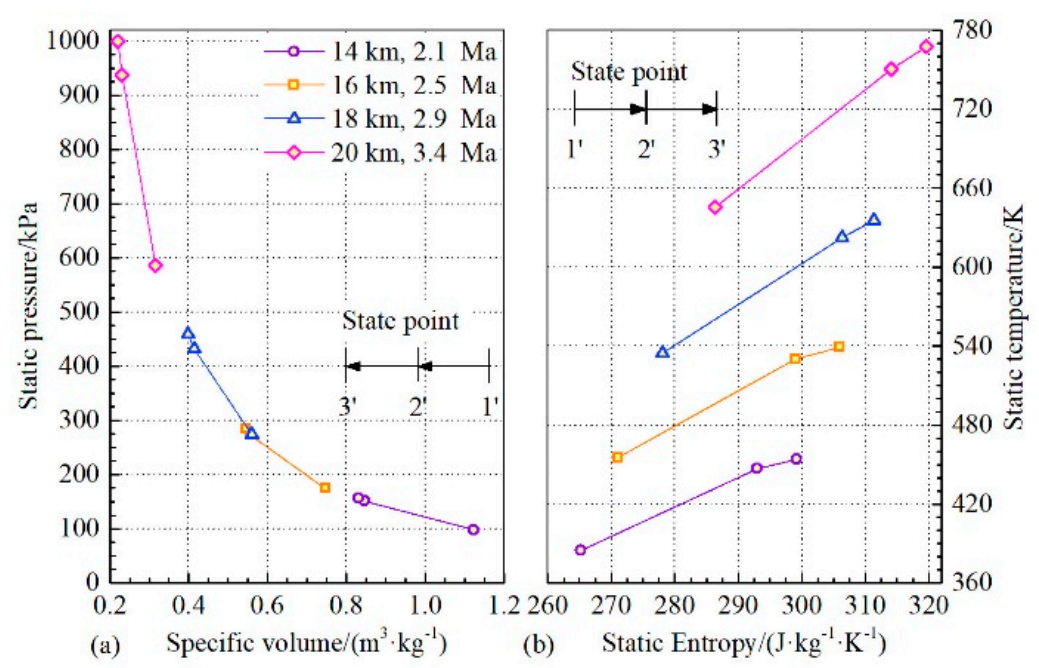

Figure 7. Thermodynamic process lines for (a): pressure-volume diagram and (b): temperature-entropy diagram at different flight Mach numbers with $45 \mathrm{kPa}$ dynamic pressure.

For different thermodynamic states above, it is necessary to know about the influence of blade loading, as shown in Figure 8. The blade loading pressure on the pressure surface and suction surface visibly enlarges both along the span direction and as Mach increases. This phenomenon can be ascribed primarily to a more compression consumption work of compressor, which contributes to the air at high Mach flight. Then, for the rotor blade loading distribution of pressure (Figure 8a), it can be seen that, within 0.4-0.6 streamwise of the blade, a flow separation area exists on the suction side where the strength of flow separation becomes greater as flight Mach increases. In addition, for the loading distribution of rotor and stator blades, it can be observed that the wake flow range also enlarges with an increase in Mach due to a larger inverse pressure gradient. From the results, it can also be deduced that: (1) the radial adverse pressure gradient in the rotor domain gradually increases along span direction; (2) the radial adverse pressure gradient decreases as flight Mach increases. 

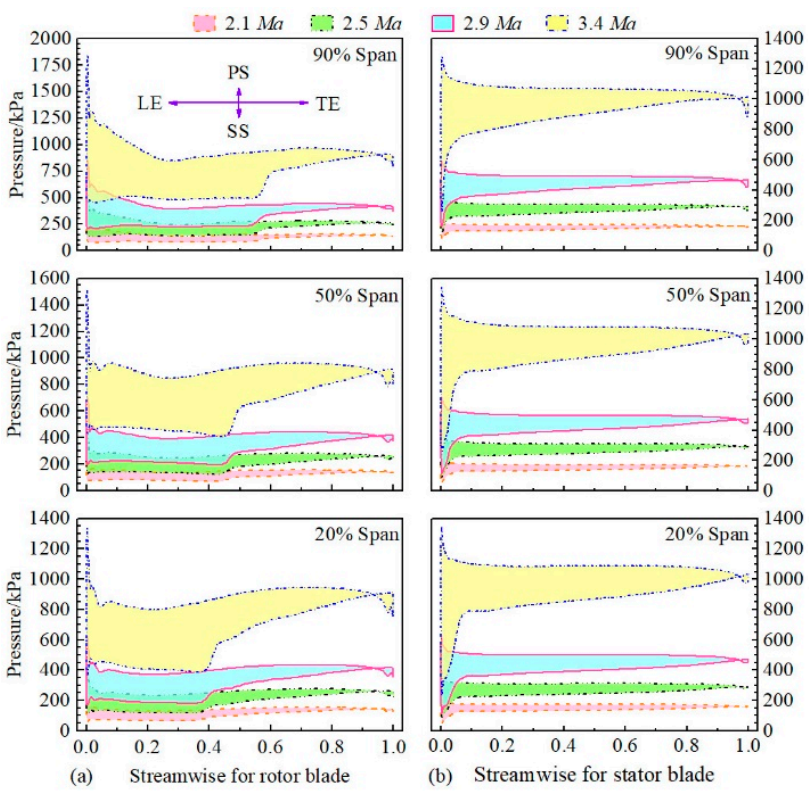

Figure 8. Blade loading distribution of pressure along $20 \%, 50 \%$, and $90 \%$ span locations for (a): rotor blade and (b): stator blade at different flight Mach with $45 \mathrm{kPa}$ dynamic pressure.

Since the turbulence flow, tip leakage flow, secondary flow at the radial direction and the blade wake flow will all result in a loss inside the compressor, the definition of entropy increase $(\Delta S)$ can be used for the quantitative evaluation of flow loss in the compressor, as expressed in Equation (2).

$$
\Delta S=\frac{\bar{C}_{p}}{\bar{\kappa}} \ln \left[\left(p_{\mathrm{t}} / p_{\mathrm{t}, 1},\right)^{1-\bar{\kappa}}\left(T_{\mathrm{t}} / T_{\mathrm{t}, 1},\right)^{\bar{\kappa}}\right]
$$

where, $\bar{C}_{p}$ and $\bar{\kappa}$ are averaged values between the compressor inlet and concerned location due to the consideration of variation specific heat.

It is necessary to know about the effect of the loading on flow loss near the wall boundary layer of blades. Figure 9 compares the near-wall loss distributions from $20 \%$ to $90 \%$ span directions for rotor and stator blades at different flight Mach with $45 \mathrm{kPa}$ dynamic pressure. As depicted in the figure, the entropy increase on the pressure surface is larger than that on the suction surface. For wall boundary layer loss on the rotor blade (Figure 9a), the average entropy increase drops from $164.6 \mathrm{~J} /(\mathrm{kg} \cdot \mathrm{K})$ to $141.3 \mathrm{~J} /(\mathrm{kg} \cdot \mathrm{K})$ at $20 \%$ span, from $187.5 \mathrm{~J} /(\mathrm{kg} \cdot \mathrm{K})$ to $164.0 \mathrm{~J} /(\mathrm{kg} \cdot \mathrm{K})$ at $50 \%$ span and from $216.8 \mathrm{~J} /(\mathrm{kg} \cdot \mathrm{K})$ to $191.9 \mathrm{~J} /(\mathrm{kg} \cdot \mathrm{K})$ at $90 \%$ span, respectively, from 2.1 Ma to 3.4 Ma. This phenomenon signifies that the entropy increase from 2.1 Ma to $3.4 \mathrm{Ma}$ decreases by $14.15 \%$ at a $20 \%$ span, $12.53 \%$ at a $50 \%$ span and $11.49 \%$ at a $90 \%$ span. In addition, the entropy increase at $90 \%$ span is 1.32 -times and 1.36-times as large as that at a $20 \%$ span, respectively, for $2.1 \mathrm{Ma}$ and 3.4 Ma. Simultaneously, for wall boundary layer loss on the stator blade (Figure $9 \mathrm{~b}$ ), the average entropy increase reduces from 107.0 to $92.8 \mathrm{~J} /(\mathrm{kg} \cdot \mathrm{K}$ ) at a $20 \%$ span, from $111.5 \mathrm{~J} /(\mathrm{kg} \cdot \mathrm{K})$ to $99.4 \mathrm{~J} /(\mathrm{kg} \cdot \mathrm{K})$ at a $50 \%$ span and from $110.5 \mathrm{~J} /(\mathrm{kg} \cdot \mathrm{K})$ to $105.0 \mathrm{~J} /(\mathrm{kg} \cdot \mathrm{K})$ at a 90\% span, respectively, from 2.1 Ma to 3.4 Ma, signifying that, from $2.1 \mathrm{Ma}$ to $3.4 \mathrm{Ma}$, it reduces by $13.3 \%$ at a $20 \%$ span, $10.9 \%$ at a $50 \%$ and $5.0 \%$ at a $90 \%$ span. Then, it is 1.03 -times and 1.13 -times at a $90 \%$ span as large as that at a $20 \%$ span, respectively, for $2.1 \mathrm{Ma}$ and $3.4 \mathrm{Ma}$. Thus, the results show that the loss inside the wall boundary gradually increases from the hub to shroud, indicating that: (a) the average adverse pressure gradient near the blade wall increases from hub to shroud; (b) the adverse pressure gradient will decrease in the radial direction as Mach number increases; (c) a larger flow loss exist close to the tip region. 

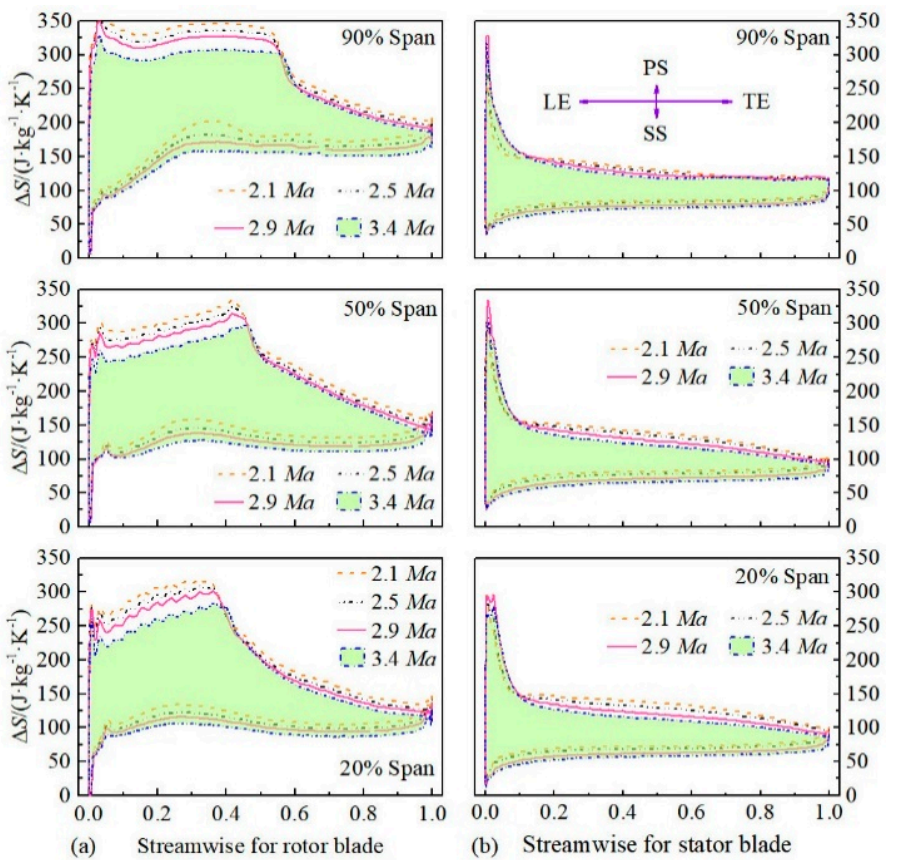

Figure 9. Loss distributions inside wall boundary layers of: (a) rotor blade and (b) stator blade along $20 \%, 50 \%$, and $90 \%$ span locations at different flight Mach with $45 \mathrm{kPa}$ dynamic pressure.

Notably, it is interesting that, after a 0.4-1.0 streamwise region at the pressure surface of the rotor blade, the entropy increase gradually reduces because the direction of the pressure gradient is the same as the airflow to lead to a steadier flow of air. Furthermore, the entropy increase reduction at low Mach lags behind than at a high Mach on the pressure side of the rotor blade. Especially, the suction side of the rotor blade is dominated by a strong adverse pressure gradient to lead to a flow separation easily. This flow separation points at a high Mach number which moves forward relative to low Mach number.

In order to better understand flow field losses, Figure 10 presents a schematic diagram of the streamwise and circumferential locations inside the blade passage.

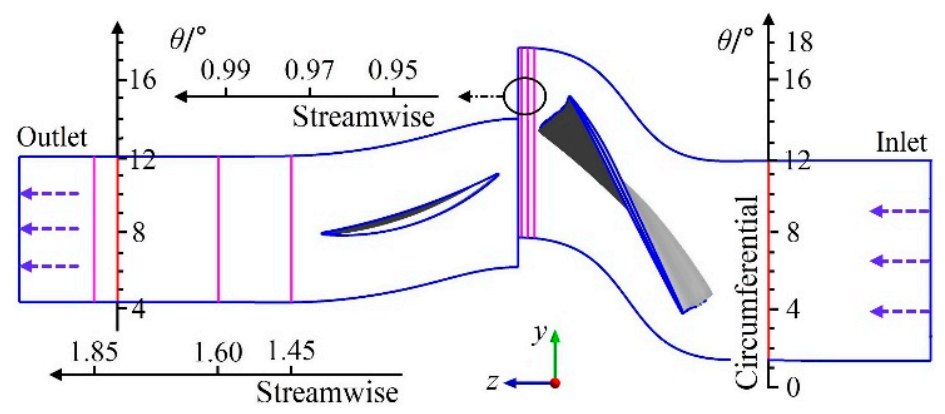

Figure 10. A schematic diagram of the streamwise and circumferential locations in the Stage35 compressor.

Since the separated flow breaking away from the blade boundary layer is not conducive to the steady flow of downstream air, Figure 11, Figure 12 reveal the influence of different Mach on flow loss, respectively, at the 0.97 streamwise (i.e., rotor blade outlet) and 1.45 streamwise (i.e., stator blade outlet). As it is shown, the entropy increase in the distribution from hub to shroud is based on a circumferential averaging method, which is calculated as a mass flow average over the corresponding circular band. The entropy increase within the wall boundary layers near the hub and shroud is higher than that in the mainstream region. The flow loss gradually increases in the mainstream region, 
and this discovery substantiates the above viewpoints in Figure 9. Typically, from the results, the most important observation can be drawn from boundary layer loss distributions, which can be observed as the boundary layer thickness decreases as Mach number increases, resulting in a lower flow loss at a high Mach number. These phenomena primarily contribute to the reduction in the turbulence core area of mainstream increases with the increment of Mach number-that is, the thickness of the turbulence region within the wall boundary layer decrease.
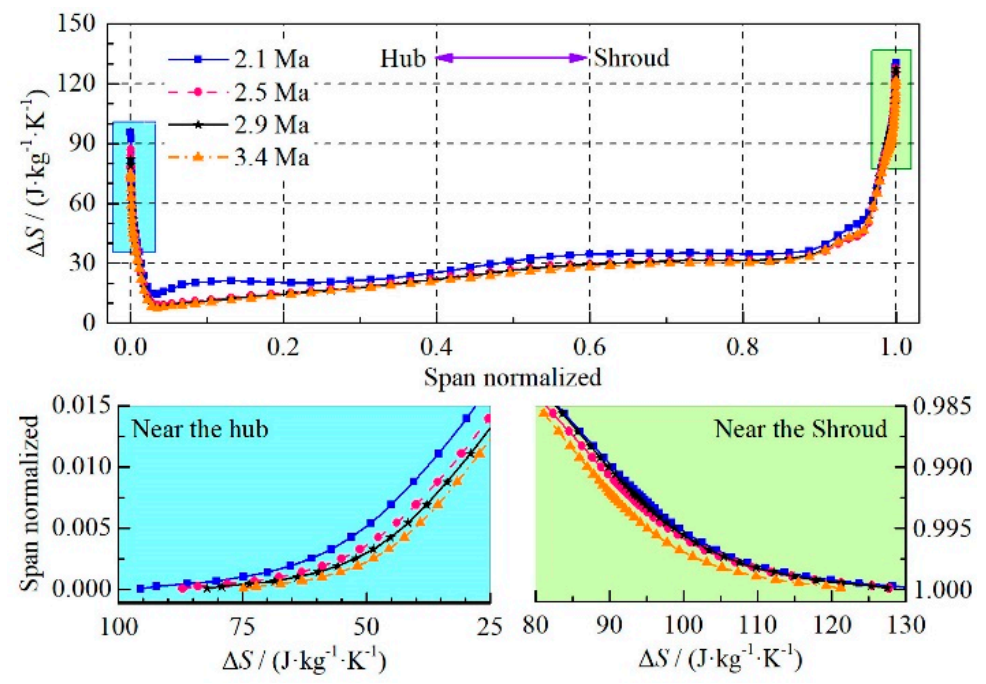

Figure 11. Loss distributions by circumferential averaging from hub to shroud at the 0.97 streamwise location for different flight Mach.
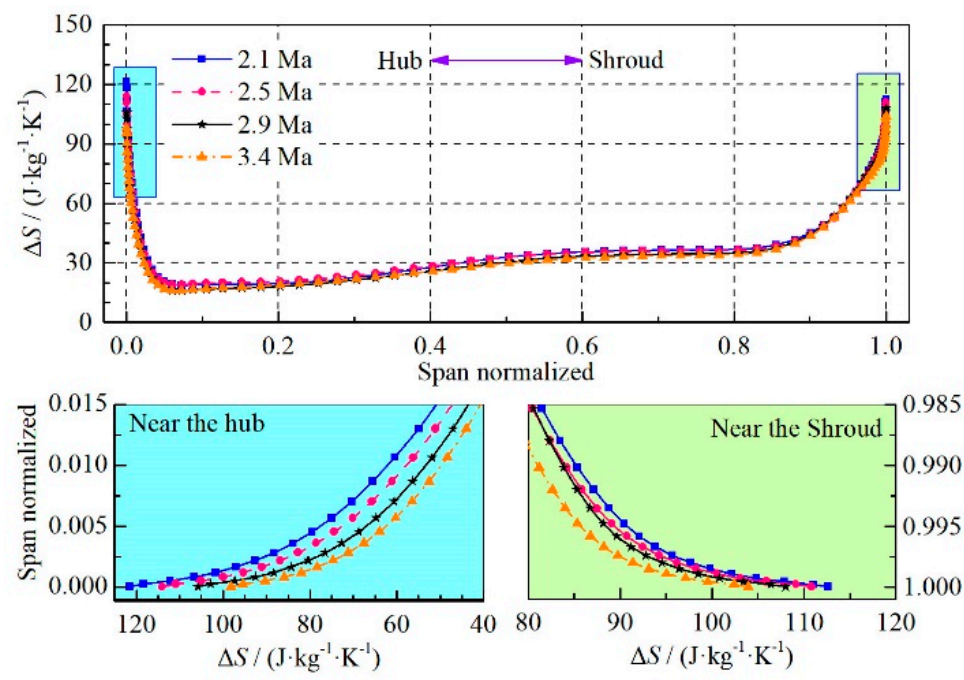

Figure 12. Loss distributions by circumferential averaging from hub to shroud at the 1.45 streamwise location for different flight Mach.

\subsection{Analysis of End Wall Boundary Layer Loss}

For a better understanding of loss distribution close to the end wall of hub and shroud, Figure 13 shows three monitored lines which are located inside the viscous sublayer (i.e., HUB-1st and SHR-1st), a buffer layer (i.e., HUB-2nd and SHR-2nd), and a fully turbulent region (i.e., HUB-3rd and SHR-3rd). 


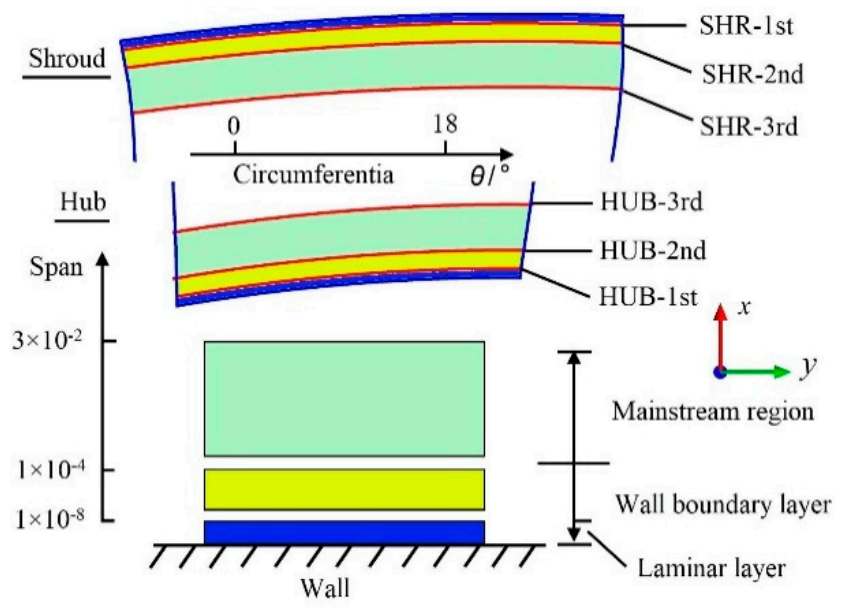

Figure 13. Schematic diagram of the wall boundary layer at circumferential direction close to the hub and shroud.

The following is to investigate the end wall boundary layer loss after the rotor blade outlet (i.e., from 0.95 to 0.99 streamwise) and after the stator blade outlet (i.e., from 1.45 to 1.85 streamwise), where the schematic diagram is shown in Figure 10. Figures 14 and 15 give the entropy increase distributions inside the boundary layer at the circumferential direction for 2.1 $\mathrm{Ma}$ after the rotor and stator outlets, respectively. As depicted in Figure 14, the wake flow has a great influence on the entropy increase distribution close to the hub and shroud, leading to a significant increase in loss. Notably, the entropy increase first enhances and then decreases along the circumferential direction from $\theta=7.2^{\circ}$ to $\theta=18^{\circ}$, ascribing that the circumferential adverse pressure gradient on the pressure side of the rotor blade is higher than that on the suction side. In contrast, the circumferential adverse pressure gradient at the pressure side of stator blade will be less than that at the suction side from $\theta=4^{\circ}$ to $\theta=12^{\circ}$.
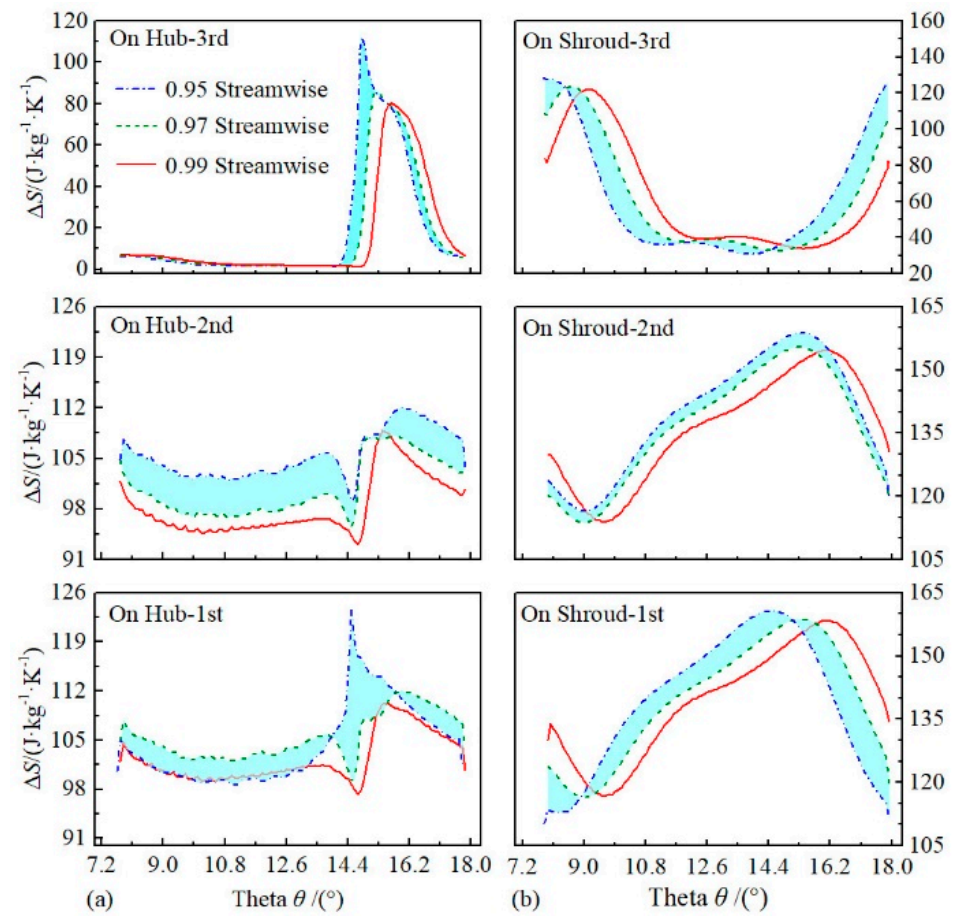

Figure 14. Loss distributions close to (a): the hub wall and (b): shroud wall along the circumferential direction at the $0.95,0.97$ and 0.99 streamwise locations with $2.1 \mathrm{Ma}$. 

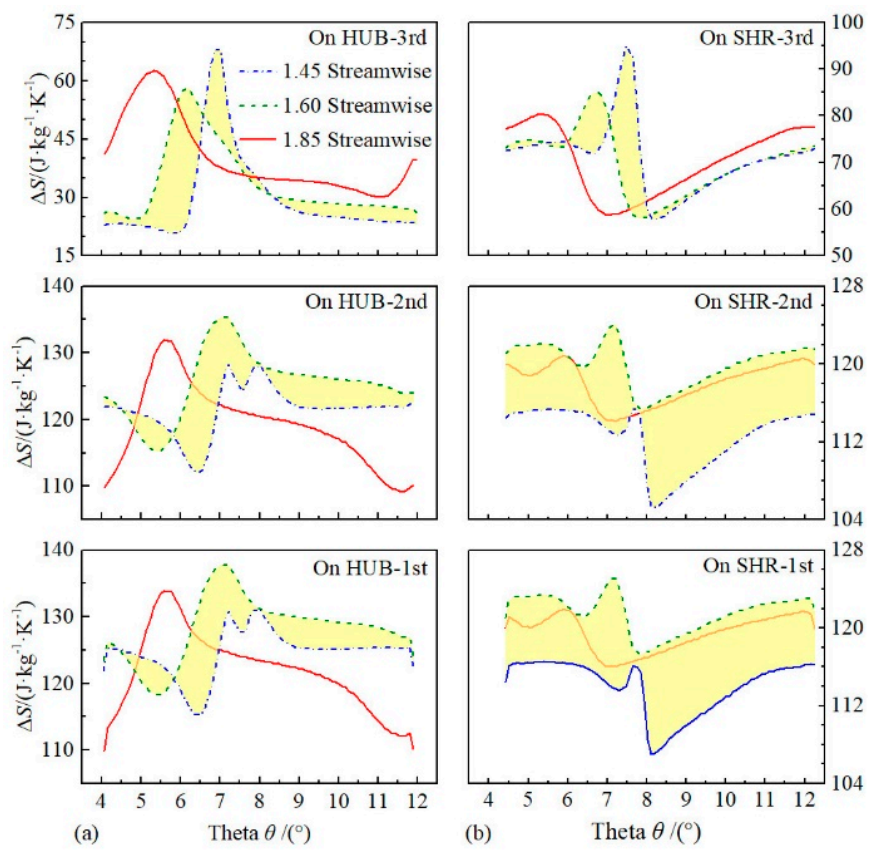

Figure 15. Loss distributions close to (a): the hub wall and (b): shroud wall along the circumferential direction at the $1.45,1.60$ and 1.85 streamwise locations with $2.1 \mathrm{Ma}$.

By comparison, with the entropy increase located inside the viscous sublayer, transition layer, and fully developed turbulent flow region, locating at the 0.95, 0.97 and 0.99 streamwise (Figure 14), the averaged entropy increases on the Hub-1st line are $104.30 \mathrm{~J} /(\mathrm{kg} \cdot \mathrm{K}), 105.46 \mathrm{~J} /(\mathrm{kg} \cdot \mathrm{K})$ and $102.34 \mathrm{~J} /(\mathrm{kg} \cdot \mathrm{K})$, respectively; which correspond to to $105.46 \mathrm{~J} /(\mathrm{kg} \cdot \mathrm{K}), 100.85 \mathrm{~J} /(\mathrm{kg} \cdot \mathrm{K})$ and $98.23 \mathrm{~J} /(\mathrm{kg} \cdot \mathrm{K})$ on the HUB-2nd line.; which correspond to $17.86 \mathrm{~J} /(\mathrm{kg} \cdot \mathrm{K}), 15.93 \mathrm{~J} /(\mathrm{kg} \cdot \mathrm{K})$ and $15.04 \mathrm{~J} /(\mathrm{kg} \cdot \mathrm{K})$ on the HUB-3rd, which correspond to $139.07 \mathrm{~J} /(\mathrm{kg} \cdot \mathrm{K}), 139.42 \mathrm{~J} /(\mathrm{kg} \cdot \mathrm{K})$ and $139.47 \mathrm{~J} /(\mathrm{kg} \cdot \mathrm{K})$ on the SHR-1st line; which correspond to $139.42 \mathrm{~J} /(\mathrm{kg} \cdot \mathrm{K}), 136.32 \mathrm{~J} /(\mathrm{kg} \cdot \mathrm{K})$ and $136.06 \mathrm{~J} /(\mathrm{kg} \cdot \mathrm{K})$ on the SHR-2nd line; which correspond to $61.07 \mathrm{~J} /(\mathrm{kg} \cdot \mathrm{K}), 61.18 \mathrm{~J} /(\mathrm{kg} \cdot \mathrm{K})$ and $61.43 \mathrm{~J} /(\mathrm{kg} \cdot \mathrm{K})$ on the SHR-3rd line. Accordingly, the entropy increase close to the hub presents a slight decreasing trend from 0.95 to 0.99 streamwise; however, the entropy increase near the shroud shows an increasing trend. Furthermore, the entropy increase rise close to the shroud enhances by $24.36-26.62 \%$ in the laminar layer, $24.36-27.80 \%$ in the buffer layer and $70.75-75.52 \%$ in the fully developed turbulent flow region, relative to that close to the hub. These phenomena can be ascribed to the tip leakage flow and secondary flow along the radial direction, which are of importance for the effect of loss inside the end wall boundary layer of the shroud. In addition, it can be deduced that, after the rotor blade exit, the thicknesses of the wall boundary layer for the hub and shroud walls gradually reduce and enhance along the streamwise, respectively.

For the entropy increase located at the 1.45, 1.60 and 1.85 streamwise locations (Figure 15), the averaged entropy increases on the Hub-1st line are $124.66 \mathrm{~J} /(\mathrm{kg} \cdot \mathrm{K}), 128.26 \mathrm{~J} /(\mathrm{kg} \cdot \mathrm{K})$ and 121.83 $\mathrm{J} /(\mathrm{kg} \cdot \mathrm{K})$, respectively; which correspond to $121.47 \mathrm{~J} /(\mathrm{kg} \cdot \mathrm{K}), 125.39 \mathrm{~J} /(\mathrm{kg} \cdot \mathrm{K})$ and $119.16 \mathrm{~J} /(\mathrm{kg} \cdot \mathrm{K})$ on the HUB-2nd line; which correspond to $29.57 \mathrm{~J} /(\mathrm{kg} \cdot \mathrm{K}), 33.64 \mathrm{~J} /(\mathrm{kg} \cdot \mathrm{K})$ and $40.42 \mathrm{~J} /(\mathrm{kg} \cdot \mathrm{K})$ on the HUB-3rd; which correspond $114.02 \mathrm{~J} /(\mathrm{kg} \cdot \mathrm{K}), 121.55 \mathrm{~J} /(\mathrm{kg} \cdot \mathrm{K})$ and $119.40 \mathrm{~J} /(\mathrm{kg} \cdot \mathrm{K})$ on the SHR-1st line; which correspond to $112.60 \mathrm{~J} /(\mathrm{kg} \cdot \mathrm{K}), 120.04 \mathrm{~J} /(\mathrm{kg} \cdot \mathrm{K})$ and $118.01 \mathrm{~J} /(\mathrm{kg} \cdot \mathrm{K})$ on the SHR-2nd line; which correspond to $71.07 \mathrm{~J} /(\mathrm{kg} \cdot \mathrm{K}), 70.08 \mathrm{~J} /(\mathrm{kg} \cdot \mathrm{K})$ and $70.44 \mathrm{~J} /(\mathrm{kg} \cdot \mathrm{K})$ on the SHR-3rd line. It can be concluded that the entropy increase from 1.45 to 1.85 streamwise shows a decreasing trend and an increasing trend inside the hub and shroud wall boundary layers, respectively. Meanwhile, the entropy increase reduction in the shroud wall boundary layer decreases by $1.99-8.54 \%$ in the viscous sublayer and $0.97-7.30 \%$ in the buffer layer, relative to that close to the hub. Within the fully developed turbulent flow region, however, the entropy increase rise close to the shroud enhances by $42.62-58.39 \%$ relative to that close to the hub. It is an interesting observation that the tip leakage flow results in the increase in the loss 
inside the shroud wall boundary layer by comparison with the loss distributions between the rotor and the stator domain.

With the increase in flight Mach number to 3.4, Figures 16 and 17 give the entropy increase distributions inside the boundary layer at circumferential direction after the rotor and stator outlets, respectively. As depicted in the Figures, the entropy increase distribution cannot change too much but can affect the adverse pressure gradient as flight Mach enhances. For the entropy increase, located at the 0.95, 0.97 and 0.99 streamwise (Figure 16), the averaged entropy increases on the Hub-1st line are $83.15 \mathrm{~J} /(\mathrm{kg} \cdot \mathrm{K}), 84.65 \mathrm{~J} /(\mathrm{kg} \cdot \mathrm{K})$ and $82.91 \mathrm{~J} /(\mathrm{kg} \cdot \mathrm{K})$, respectively; which correspond to $79.13 \mathrm{~J} /(\mathrm{kg} \cdot \mathrm{K}), 80.22 \mathrm{~J} /(\mathrm{kg} \cdot \mathrm{K})$ and $78.97 \mathrm{~J} /(\mathrm{kg} \cdot \mathrm{K})$ on the HUB-2nd line; which correspond to $13.9 \mathrm{~J} /(\mathrm{kg} \cdot \mathrm{K})$, $12.26 \mathrm{~J} /(\mathrm{kg} \cdot \mathrm{K})$ and $11.75 \mathrm{~J} /(\mathrm{kg} \cdot \mathrm{K})$ on the HUB-3rd; which correspond to $131.13 \mathrm{~J} /(\mathrm{kg} \cdot \mathrm{K}), 131.23 \mathrm{~J} /(\mathrm{kg} \cdot \mathrm{K})$ and $130.98 \mathrm{~J} /(\mathrm{kg} \cdot \mathrm{K})$ on the SHR-1st line; which correspond to $128.13 \mathrm{~J} /(\mathrm{kg} \cdot \mathrm{K}), 128.18 \mathrm{~J} /(\mathrm{kg} \cdot \mathrm{K})$ and $127.85 \mathrm{~J} /(\mathrm{kg} \cdot \mathrm{K})$ on the SHR-2nd line; which correspond to $63.04 \mathrm{~J} /(\mathrm{kg} \cdot \mathrm{K}), 63.29 \mathrm{~J} /(\mathrm{kg} \cdot \mathrm{K})$ and $63.67 \mathrm{~J} /(\mathrm{kg} \cdot \mathrm{K})$ on the SHR-3rd line. Compared with the wall boundary layer loss from 0.95 to 0.99 streamwise in Figure 14, the averaged entropy increase reductions from 3.4 to $2.1 \mathrm{Ma}$ decrease by $18.99-20.28 \%$ on the HUB-1st line, $19.61-24.97 \%$ on the HUB-2nd line, $21.88-23.04 \%$ on the HUB-3rd line, $5.71-6.09 \%$ on the SHR-1st and 5.97-8.1\% on the SHR-2nd. From 1.45 to 1.85 streamwise (Figure 17), in addition, the averaged entropy increase reductions from 3.4 to $2.1 \mathrm{Ma}$ drop by $18.45-18.71 \%$ on the HUB-1st line, $18.82-19.03 \%$ on the HUB-2nd line, $17.69-20.16 \%$ on the HUB-3rd line, $6.88-8.28 \%$ on the SHR-1st, $7.15-8.67 \%$ on the SHR-2nd and $1.42-2.47 \%$ on the SHR-3st. From 0.95 to 0.99 streamwise, however, the averaged entropy increases rise from 3.4 to $2.1 \mathrm{Ma}$, enhanced by $3.23 \%$ to $3.65 \%$ on the SHR-3st. These phenomena illustrate that, from 2.1 Ma to 3.4 Ma: (1) the entropy increase inside the wall boundary layer gradually decreases as flight Mach number increases; (2) the entropy increase reduction is larger inside the hub boundary layer than inside the shroud boundary layer; (3) the entropy increase within the fully developed turbulent flow region will enhance near the rotor shroud.
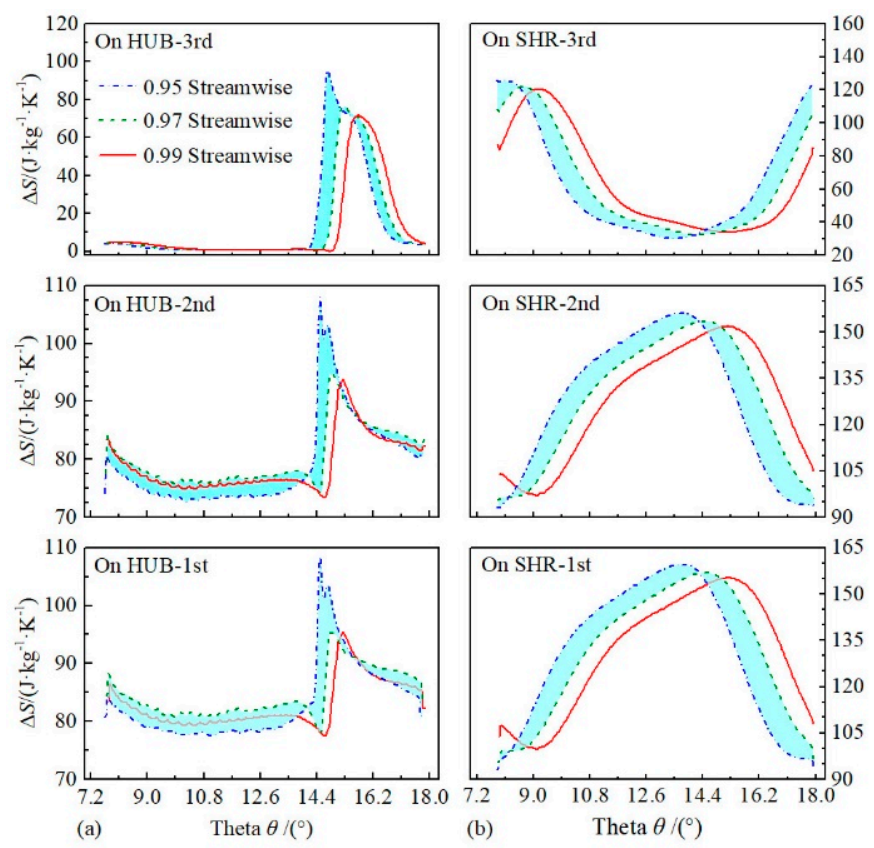

Figure 16. Loss distributions close to (a): the hub wall and (b): shroud wall along the circumferential direction at the $0.95,0.97$ and 0.99 streamwise locations with $3.4 \mathrm{Ma}$. 

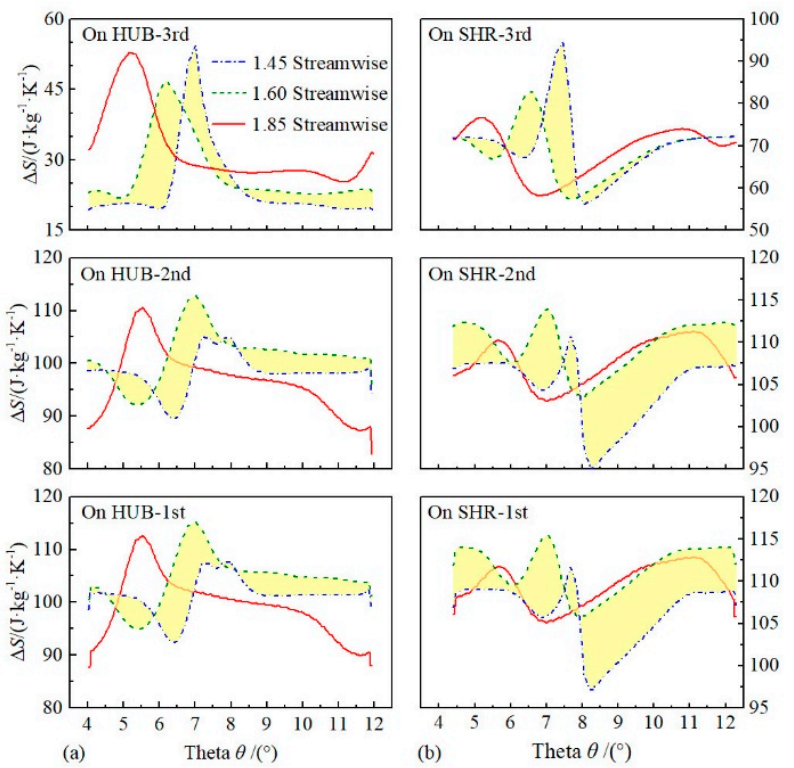

Figure 17. Loss distributions close to (a): the hub wall and (b): shroud wall along the circumferential direction at the $1.45,1.60$ and 1.85 streamwise locations with $3.4 \mathrm{Ma}$.

\section{Conclusions}

The prediction of the wall boundary layer loss at high Mach flight was investigated and discussed in this study. The calculation accuracy for results was qualified by comparing with the experimental data. Conclusions are summarized as follows:

According to the wall boundary layer loss distribution in the compressor, the tip leakage flow and secondary flow in the radial direction are of importance for the effect of loss inside the shroud boundary layer, so that a larger boundary layer loss exists close to the tip region. Then, the wake flow has a great influence on the entropy increase distribution close to the hub and shroud, leading to a significant increase in loss. Since the thickness of the turbulence region within the wall boundary layer decreases as flight Mach number increases, the boundary layer thickness shrinks, resulting in a lower flow loss at high Mach number.

The results show that the radial adverse pressure gradient in the rotor domain gradually increases along span direction and decreases as flight Mach increases. Meanwhile, the circumferential adverse pressure gradient on the pressure side of the rotor and stator blades is higher and less than that on the suction side, respectively.

At 2.1 Mach number, the entropy increase along the streamwise shows a decreasing trend and an increasing trend inside the hub and shroud wall boundary layers, respectively. Simultaneously, within the rotor domain, the entropy increase rise close to the shroud enhances by $24.36-26.62 \%$ in the viscous sublayer, $24.36-27.80 \%$ in the buffer layer and $70.75-75.52 \%$ in the fully developed turbulent flow region, relative to that close to the hub. In the stator domain, the entropy increase reduction in the shroud boundary layer decreases by $1.99-8.54 \%$ in the viscous sublayer and $0.97-7.30 \%$ in the buffer layer, relative to that close to the hub. Within the fully developed turbulent flow region, however, the entropy increase rise close to the shroud enhances by $42.62-58.39 \%$, relative to that close to the hub.

With the increase in flight Mach number from 2.1 to 3.4, the averaged entropy increase reductions in the rotor domain decrease by $18.99-24.97 \%$ within the hub boundary layer and $5.71-8.1 \%$ within the shroud boundary layer; in the stator domain, this drops by $18.45-19.03 \%$ inside the hub boundary layer and $6.88-8.67 \%$ inside the shroud boundary layer. So, the entropy increase reduction is larger inside the hub boundary layer than inside the shroud boundary layer, as Mach number increases from 2.1 to 3.4. 
Author Contributions: Conceptualization, F.W., L.G., L.Y., A.L. and H.Z.; methodology, F.W., L.G., L.Y., A.L. and H.Z.; software, F.W. and A.L.; validation, A.L. and H.Z.; formal analysis, F.W., L.G., L.Y., A.L. and H.Z.; investigation, F.W. and A.L.; writing - original draft preparation, F.W. and A.L.; writing-review and editing, F.W., L.G., L.Y., A.L. and H.Z. supervision, L.G., A.L. and H.Z. All authors have read and agreed to the published version of the manuscript.

Funding: This research received no external funding.

Conflicts of Interest: The authors declare no conflict of interest.

\section{References}

1. Lin, A.; Zhou, J.; Tian, X.; Zheng, Q.; Zhang, H. Effective boundary conditions and numerical method for flow characteristics of aeroengine compressor at high Mach flight. J. Appl. Fluid Mech. 2019, 12, 845-855. [CrossRef]

2. Jung, Y.; Jeon, H.; Jung, Y.; Lee, K.; Choi, M. Effects of recessed blade tips on stall margin in a transonic axial compressor. Aerosp. Sci. Technol. 2016, 54, 41-48. [CrossRef]

3. Lin, A.; Chang, X.; Cao, L.; Zhang, H.; Sun, L. Effect of wet steam on aerodynamic performance of low-pressure exhaust passage with last stage blade. J. Appl. Fluid Mech. 2019, 12, 1837-1845. [CrossRef]

4. Jia, X.; Zhang, H.; Zheng, Q. Numerical investigation on the effect of hot running rim seal clearance on hot gas ingestion into rotor-stator system. Appl. Therm. Eng. 2019, 152, 79-91. [CrossRef]

5. Jiang, X.; Lin, A.; Malik, A.; Chang, X.; Xu, Y. Numerical investigation on aerodynamic characteristics of exhaust passage with consideration of multi-factor components in a supercritical steam turbine. Appl. Therm. Eng. 2019, 162, 114085. [CrossRef]

6. Jiang, X.; Lin, A.; Ma, H.; Li, X.; Li, Y. Minimizing the thermal bridge through the columns in a refrigeration room. Appl. Therm. Eng. 2020, 165, 114565. [CrossRef]

7. Lin, A.; Zheng, Q.; Fawzy, H.; Luo, M.; Zhou, J.; Zhang, H. Effect of water injection cooling on flow field characteristics in the cooling section of precooled turbine-based combined cycle engine. Int. J. Heat Mass Tran. 2019, 141, 615-626. [CrossRef]

8. Lin, A.; Zheng, Q.; Jiang, Y.; Lin, X.; Zhang, H. Sensitivity of air/mist non-equilibrium phase transition cooling to transient characteristics in a compressor of gas turbine. Int. J. Heat Mass Tran. 2019, 137, 882-894. [CrossRef]

9. Lin, A.; Zhou, J.; Fawzy, H.; Zhang, H.; Zheng, Q. Evaluation of mass injection cooling on flow and heat transfer characteristics for high-temperature inlet air in a MIPCC engine. Int. J. Heat Mass Tran. 2019, 135, 620-630. [CrossRef]

10. Berdanier, R. Design of a Multi-stage Research Compressor for Cantilevered Stator Hub Clearance Flow Investigations. Master's Thesis, Purdue University, West Lafayette, IN, USA, 2012.

11. Gbadebo, S.; Cumpsty, N.; Hynes, T. Three-Dimensional Separations in Axial Compressors. J. Turbomach. 2005, 127, 331-339. [CrossRef]

12. Hanan, L.; Qiushi, L. Cantilevered stator hub leakage flow control and loss reduction using non-uniform clearances. Aerosp. Sci. Technol. 2016, 51,1-10. [CrossRef]

13. Akcayoz, E.; Vo, H.; Mahallati, A. Controlling Corner Stall Separation With Plasma Actuators in a Compressor Cascade. J. Turbomach. 2015, 138. [CrossRef]

14. Zhao, W.; Zheng, Q.; Jiang, B.; Lin, A. A Passive Control Method of Hub Corner Stall in a 1.5-Stage Axial Compressor under Low-Speed Conditions. Energies 2020, 13, 2691. [CrossRef]

15. Jiang, B.; Shi, X.; Zheng, Q. The relationship of spike stall and hub corner separation in axial compressor. Int. J. Turbo Jet Engines 2017. [CrossRef]

16. Caruana, D.; Mignosi, A.; Corrège, M.; Pourhiet, A.; Rodde, A. Buffet and buffeting control in transonic flow. Aerosp. Sci. Technol. 2005, 09, 605-616. [CrossRef]

17. Duan, Z.; Liu, Y.; Lu, L. Influence of circumferential casing grooves on transonic compressor rotor performance. Acta Aeronaut. ET Astronaut. Sin. 2014, 8, 2163-2173.

18. Chu, W.; Li, X.; Wu, Y.; Zhang, H. Reduction of end wall loss in axial compressor by using non-axisymmetric profiled end wall: A new design approach based on end wall velocity modification. Aerosp. Sci. Technol. 2016, 55, 76-91. [CrossRef] 
19. Lin, A.; Zheng, Q.; Yang, L.; Zhang, H. Effect of inlet air pre-cooling of water injection on compressor performance at high flight Mach. J. Appl. Fluid Mech. 2019, 12, 421-431. [CrossRef]

20. Reid, L.; Moore, R. Design and Overall Performance of Four Highly-Loaded, High-Speed Inlet Stages for an Advanced, High-Pressure-Ratio Core Compressor; NASA TP-1337; NASA: Washington, DC, USA, 1978.

21. Lin, A.; Sun, Y.; Zhang, H.; Lin, X.; Yang, L.; Zheng, Q. Fluctuating characteristics of air-mist mixture flow with conjugate wall-film motion in a compressor of gas turbine. Appl. Therm. Eng. 2018, 142, 779-792. [CrossRef]

22. Menter, F. Two-equation eddy-viscosity turbulence models for engineering applications. AIAA J. 1994, 32, 1598-1605. [CrossRef]

(C) 2020 by the authors. Licensee MDPI, Basel, Switzerland. This article is an open access article distributed under the terms and conditions of the Creative Commons Attribution (CC BY) license (http://creativecommons.org/licenses/by/4.0/). 